\title{
Digitalization of Ancient Sculpting Models and 3D Design Using Photogrammetry Methodology
}

\author{
T. DOVRAMADJIEV \\ Technical University of Varna,MTF, Dept. Industrial Design \\ dr.tihomir.dovramadjiev@gmail.com
}

Abstract. The digitization of ancient sculptures is particularly relevant and necessary in relation to the preservation of the cultural heritage. And the studied ancient models have their unique identity in terms of their visual and functional qualities. In parallel, the study aims to optimize the technological process related to photogrammetric measurements and calculations, technological tools and specialized software applications such as Autodesk ReCap, Blender and MeshMixer. The used models in the article are for re-presentation of popular ancient models \& artifacts from city of Varna (by the ancient name Odessos). By using a 3D print device, one of the resulting digitized models of an ancient angel will materialize by applying specific techniques to redesign its geometry. The completed $3 D$ printed item of re-designed model of ancient stone angel is only for personal and non-comercial use. One of the main point in the article is to show advanced computer techniques for teaching and studying. The information in this article has been built for helping other specialist working in digital field regarding photogrammetry. Also the material can be useful for designers, engineers, archaeologists and others in their work for the publicity of ancient treasures.

Keywords:photogrammetry, 3D, re-design, reconstruction, sculpting

\section{Introduction}

The digitization of objects, models, sculptures and artifacts with specific historic value is of particular importance in preserving the national and historical heritage. The present research purposes are:

- Exploring and optimizing photogrammetric capabilities and calculations by modern technical means;

- Optimizing the interaction between different software systems and file formats;

- Creating a quality 3D geometry of the received computer models;

- Systematizing the methodology for the transfer of information data which is applicable to the three-dimensional printing;

- Developing a re-design of an exemplary artifact for educational and non-commercial purposes; Digitalizing in 3D and preserving sample objects - artifacts with educational purpose. 
One of the realized digitized models of artifacts (re-design) is shown in figure 1

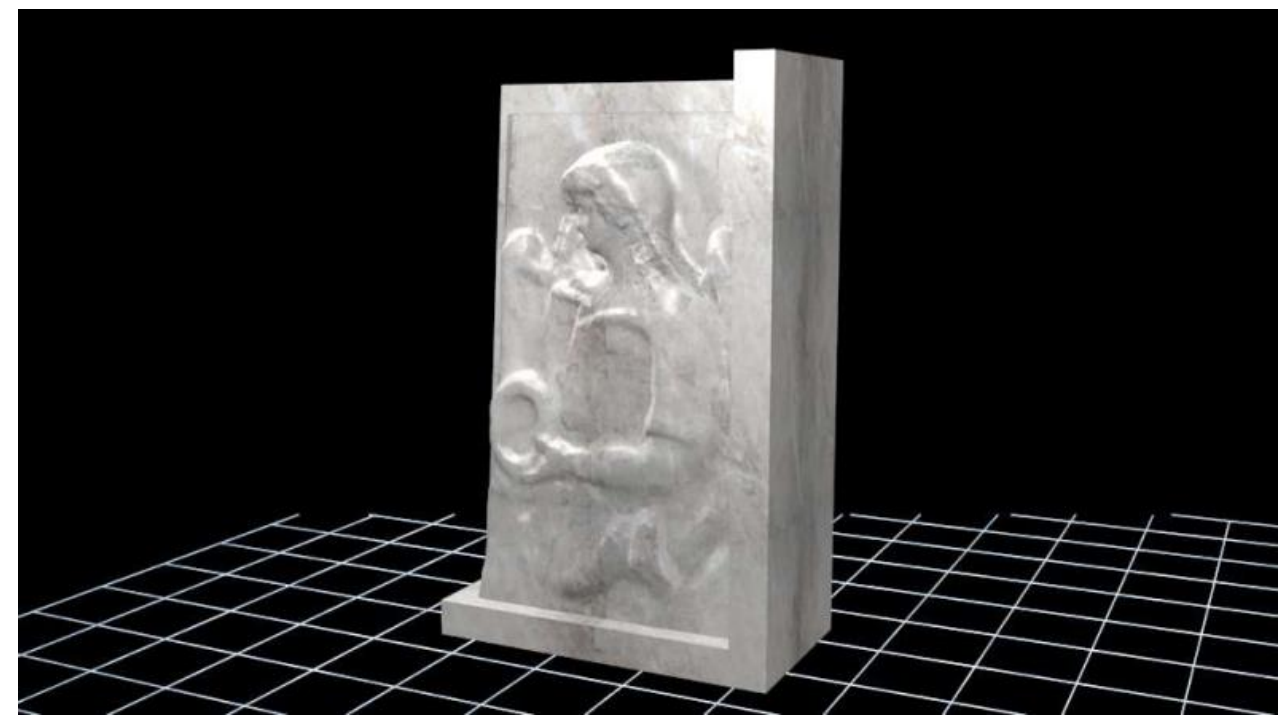

Figure 1. Photogrammetry final result: re-designed ancient angel with textures

For the study samples of ancient artifacts found in the Museum of Archaeology (figure 2 (a) [1]) in the city of Varna (Bulgaria) with an ancient name Odessos are included (figure 2 (b)[2]) logo of the municipality of Varna and figure 2 (c) [3] a geographical map of the city).
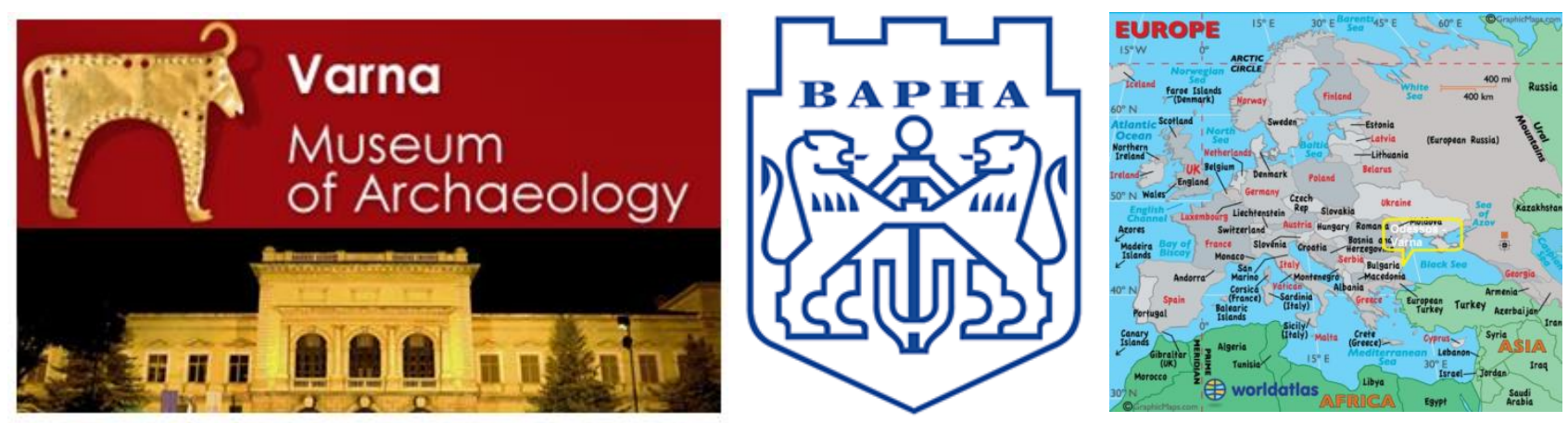

Figure 2. The Museum of Archaeology in city of Varna (a), logo of the municipality of Varna (b) and geographic location of Varna (c)

The Museum of Archeology in the city of Varna was founded by the Czech brothers archaeologists Karel and Hermann Shkorpil at the beginning of the 20th century, and the first exhibition opened in 1906.(3). The Archaeological Museum is popular worldwide with the preservation of one of the oldest golden treasures dating 4400 - $4100 \mathrm{BC}$. There are also scientific opinions concluding that besides its ancient origins $[4,5]$, the displayed gold treasure is invaluable not only for its worth but also as a model containing characteristic mathematical and geometric features of a certain importance [6, 7]. The Archaeological Museum in Varna keeps artifacts from different periods of time [8 - 10], and some of the most significant ones are: Gold earring (4th - 3rd c. BC), Marble tomb stones. Varna (5th and 4th c. BC), Golden bracelet with pearls and glass ornaments - Varna (6th C.), Beautiful mosaics of the Early Christian Cathedral of Odessos (5th century), Clay baptismal font for holy water with adjourned ornaments. Varna, Galata (5th C.), Cross-made of gold plates, which make beds for the implantation of inlays of malachite and garnet in the form of stylized plants (About 1-st millennium AD.) and other. 


\section{Methodology. Photogrammetry\& re-design}

2.1. The Photogrammetry. Photogrammetry consists of features that require certain conditions for obtaining the qualitative results of the measurements on the basis of which the geometry of the digitized models is calculated (figure 3) [11 - 13].

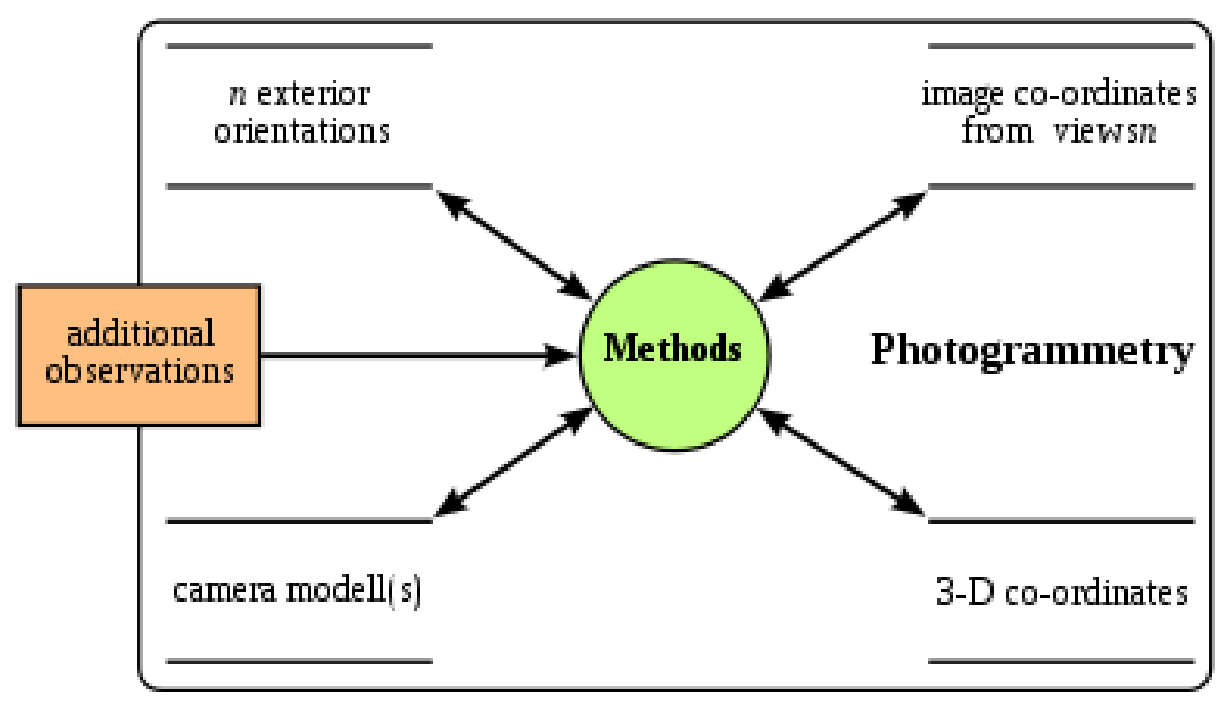

Figure 3. A data model of photogrammetry [12,13]

In the field of sculpting and archeology, where digitization of assignment models is required, photogrammetry is successfully applied [14 - 19].

2.2. The Technical Means. An useful, popular and effective software used in this science aresearch are Autodesk ReCAP, Blender and Autodesk MeshMixer (table 1). In addition to easy access to security, software applications are distinguished by their free access, with two of the programs being fully license free [20 - 22].

Table 1. An useful, popular \& effective software - Autodesk ReCAP, Blender and Autodesk MeshMixer [20 - 22].

\begin{tabular}{|c|c|}
\hline Software & License \\
\hline Autodesk ReCAP & Trial /paid \\
\hline Blender & Free \\
\hline Autodesk MeshMixer & Free \\
\hline
\end{tabular}

Using one camera $[23,24]$. and the principle of operation and interaction between Autodesk ReCAP, Blender and Autodesk MeshMixer is thoroughly presented in a source [25].

\subsection{Technical realization and digitization of real artifacts.}

The used samples are located in the territory of the Archaeological Museum in Varna (http://www.archaeo.museumvarna.com/en/). A smartphone camera is used to capture them (Lenovo, five megapixel). 
Model 1. Re-designed ancient angelin details.

For photogrammetric measurements, 24 pictures were used (figure 4)

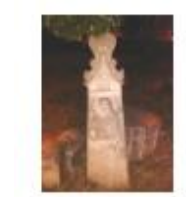

Lenovo_A1000_I MG_20180616_21 3817.jpg

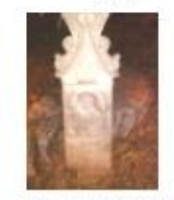

Lenovo_A1000_I MG_20180616_21

4028.jpg

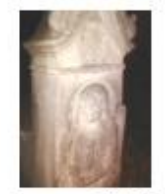

Lenovo_A1000_I MG_20180616_21

4120.jpg

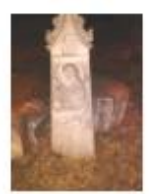

Lenovo_A1000 I MG_20180616_21 3822.jpg

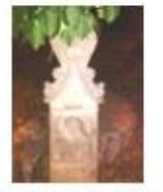

Lenovo_A1000_I MG_20180616_21 4031.jpg

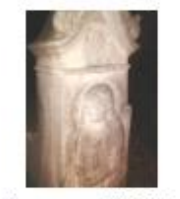

Lenovo_A1000_I MG_20180616_21 4123.jpg

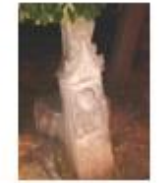

Lenovo_A1000 MG_20180616_21 3831.jpg

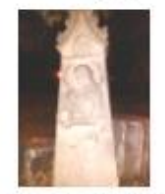

Lenovo_A1000 MG_20180616_21 4040.jpg

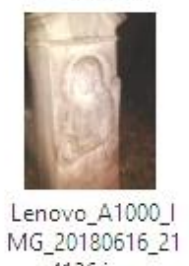

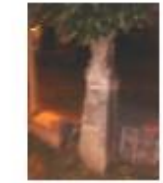

Lenovo_A1000_I MG_20180616_21 $3847 . j p g$

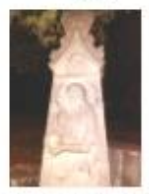

Lenovo_A1000_I MG_20180616_21 4045.jpg

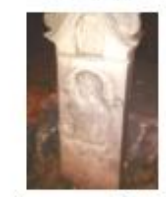

Lenovo_A1000_I MG_20180616_21

4133.jpg

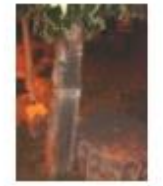

Lenovo A1000 MG_20180616_21 3906.jpg

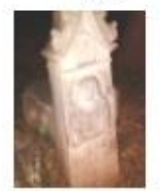

Lenovo_A1000_I MG_20180616_21 4052.jpg

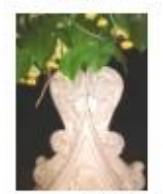

Lenovo_A1000 MG_20180616_21

$$
\text { 4141.jpg }
$$

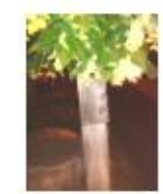

Lenovo_A1000_I MG_20180616_21 3930.jpg

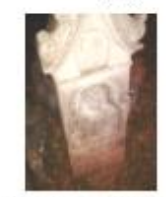

Lenovo_A1000_I MG_20180616_21 4057.jpg

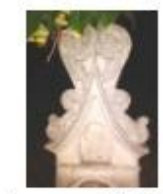

Lenovo_A1000_I MG_20180616_2

4145.jpg

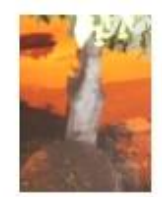

Lenovo_A1000_I MG 20180 4001.jpg

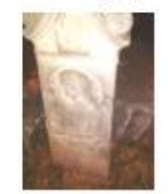

Lenovo_A1000_I MG_20180616_21 4102.jpg

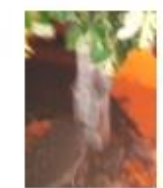

Lenovo_A1000 MG_20180616_21 4013.jpg

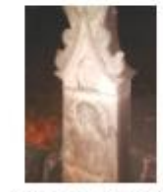

Lenovo_A1000 MG_20180616_21 4110.jpg

Figure 4.24 photos of ancient tomb with angel fragment

The resulting generated photogrammetric model in Autodesk ReCAP environment is shown in figure 5 (a) 3D model and figure 5 (b) texture
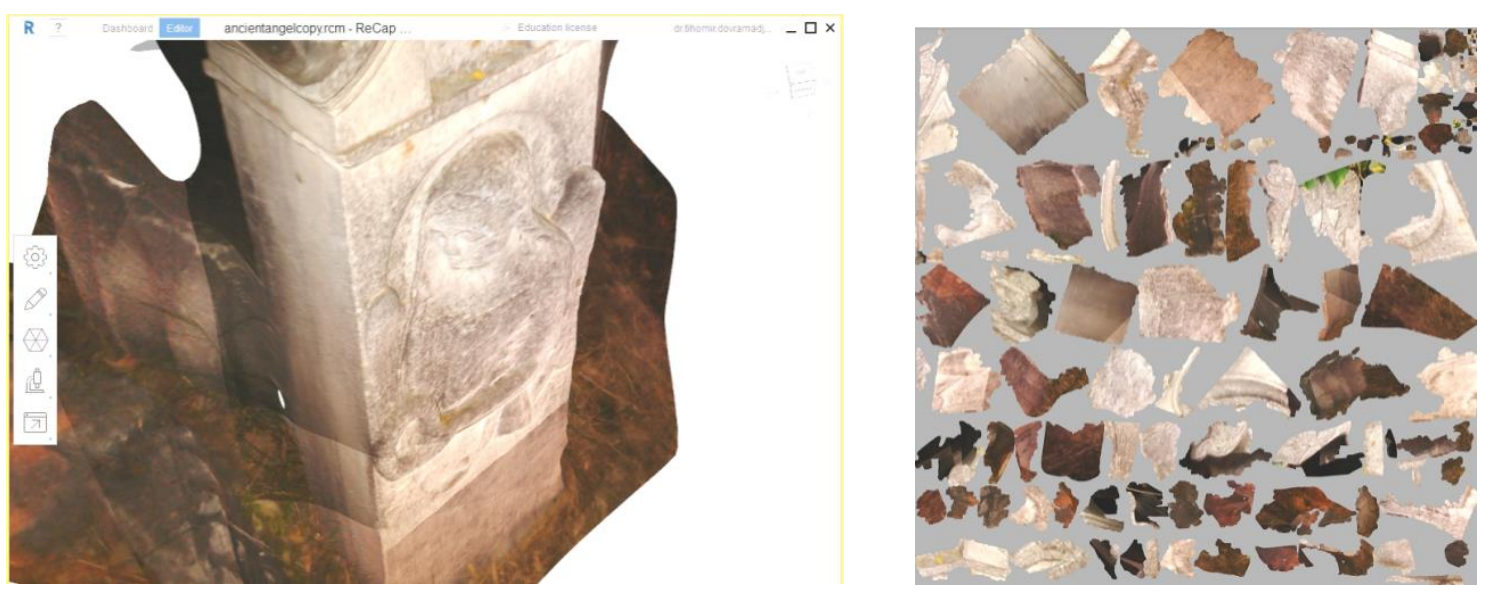

Figure 5. The generated 3D model + textures 
The model is sequentially processed in Autodesk ReCAP with slicing and in Blender with sculpting tools (figure 6).
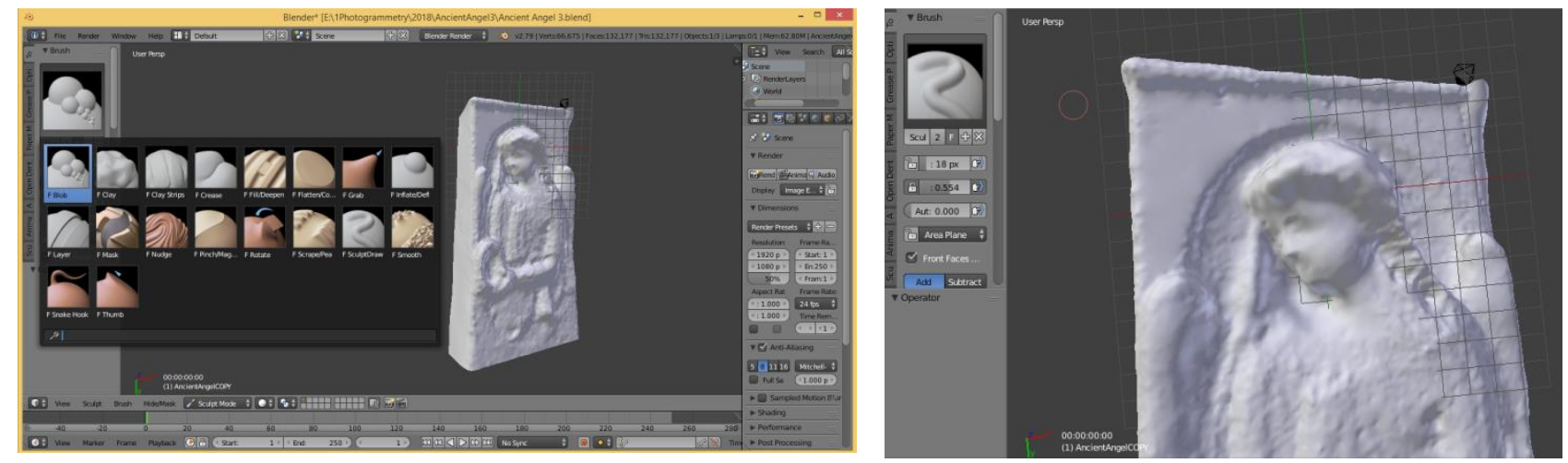

Figure 6. Sculpting and re-design of the model in Blender software

The completion of the angel + frame fragment is shown in figure 7 (a) and the polygonal mesh 7 (b)

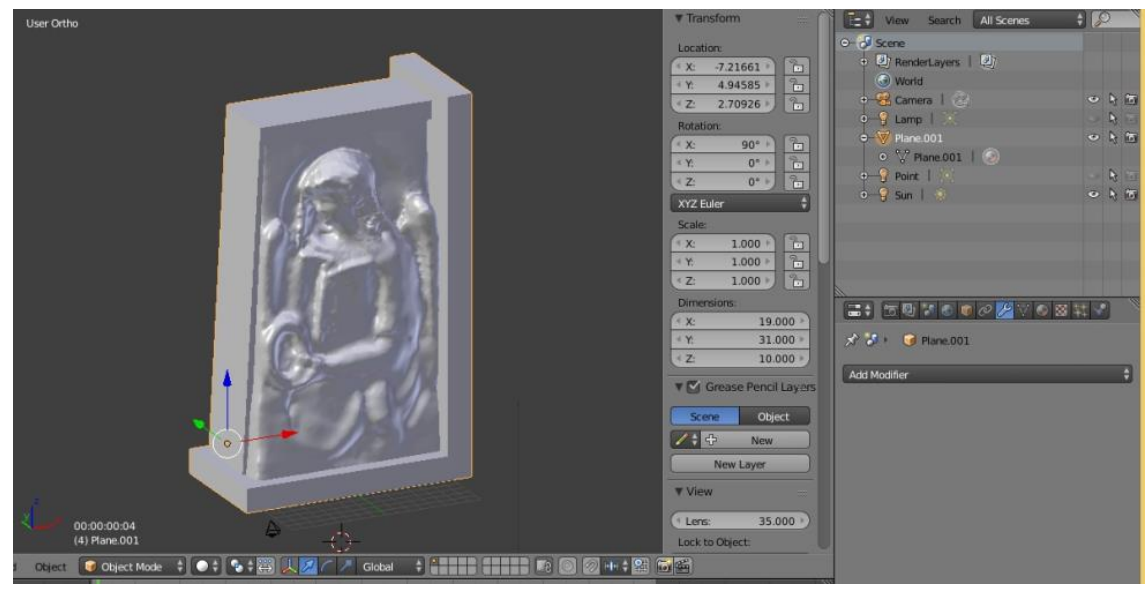

(a)

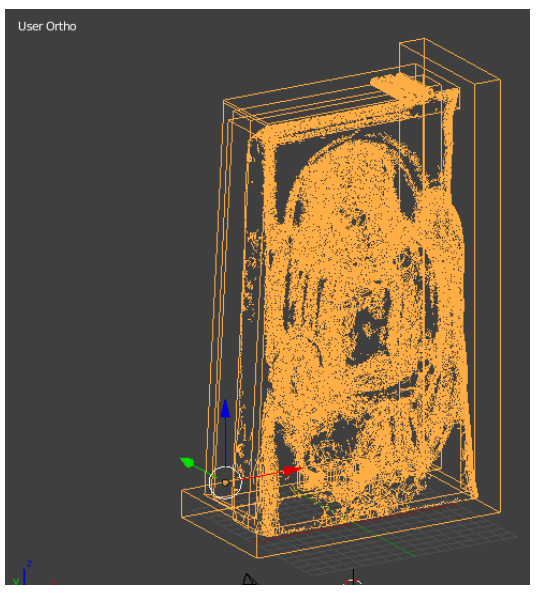

(b)

Figure 7. The angel + frame fragment (a) and the polygonal mesh (b)

The resulting model is imported into Autodesk MeshMixer in *.obj format (also is possible *.stl), where the model is optimized in Solid state and materialized with a 3D printer (Figure 8 (a) and (b)).

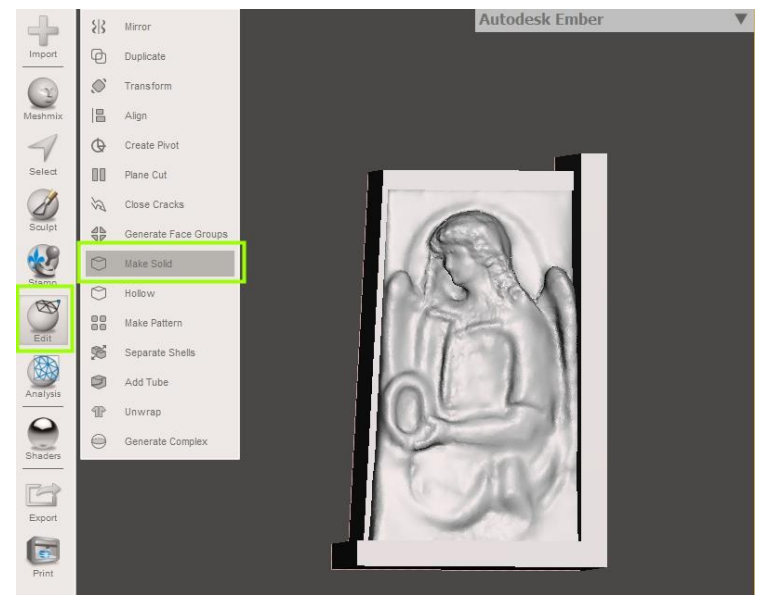

(a)

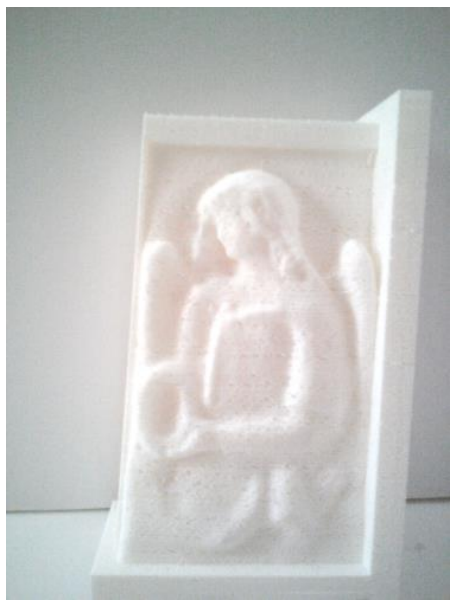

(b)

Figure 8. 3D Solid angel fragment + frame (a) and finished printed model (3D PrinterMashine - Ultimaker -2) (b) 


\section{Model 2. Ancient artifact - the marble cross}

The photogrammetry result from 21 captured photos (figure 9)

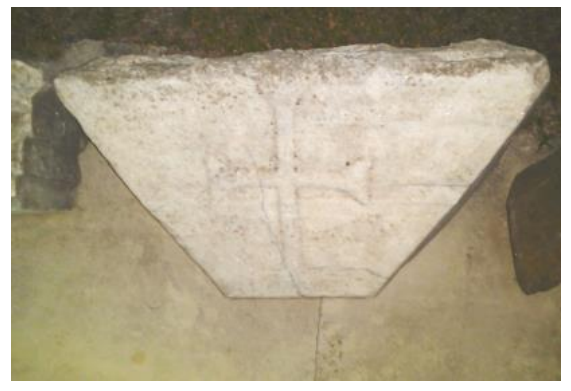

(a)

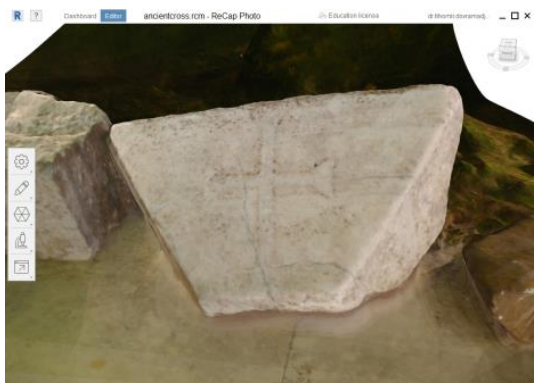

(b)

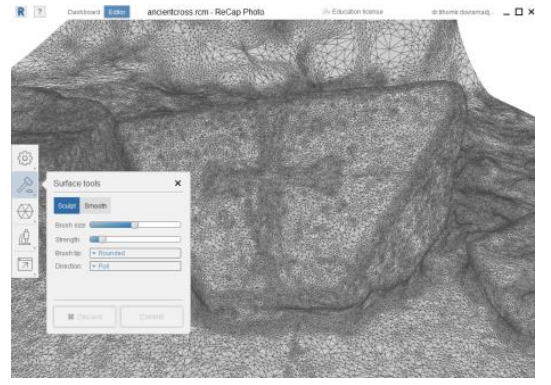

(c)

Figure 9. The the marble cross: real photo (a) 3D + texture (b) and 3D mesh (c)

\section{Model 3. Ancient artifact - the stone with grapes ornaments}

The photogrammetry result from 32 captured photos (figure 10)

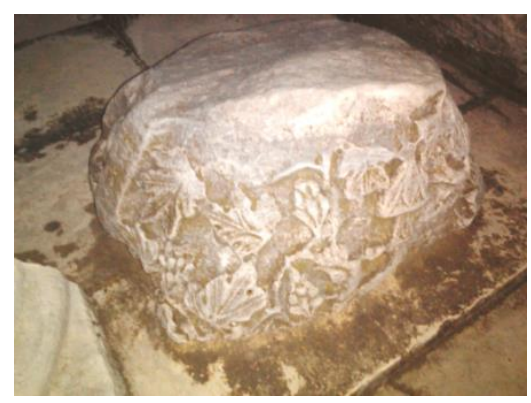

(a)

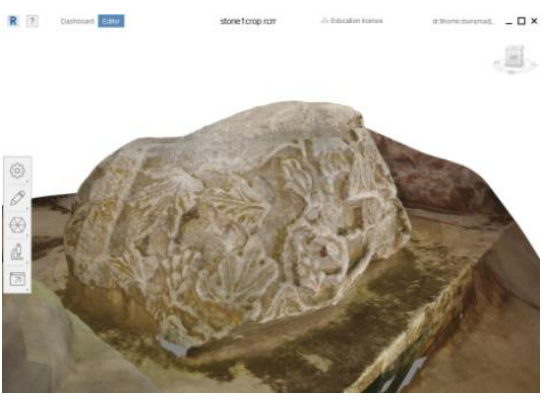

(b)

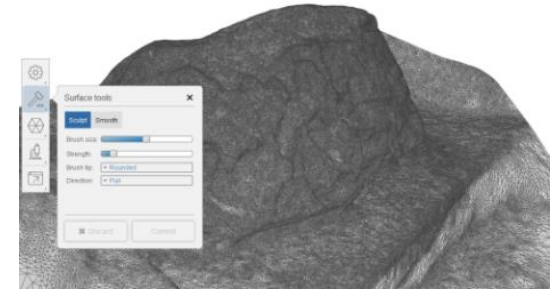

(c)

Figure 10. The stone with grapes ornaments: real photo (a) 3D + texture (b) and 3D mesh (c)

\section{Model 4. Ancient artifact - the stone voluta}

The photogrammetry result from 22 captured photos (figure 11)

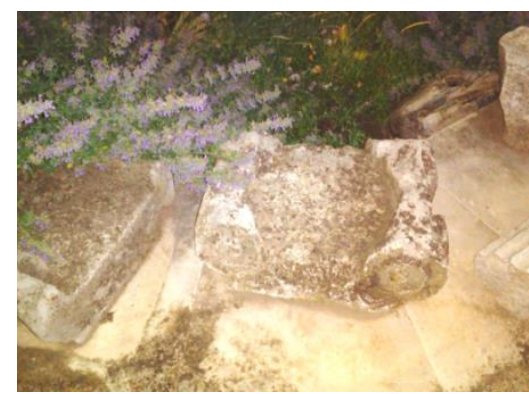

(a)

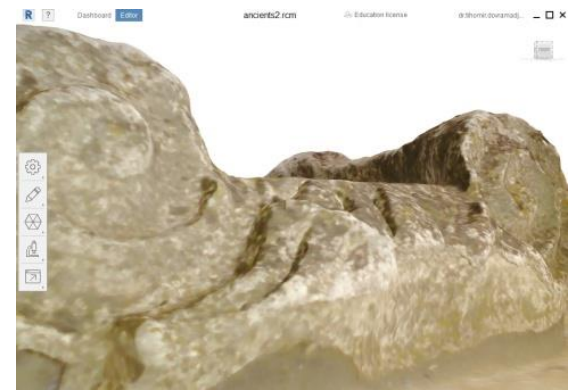

(b)

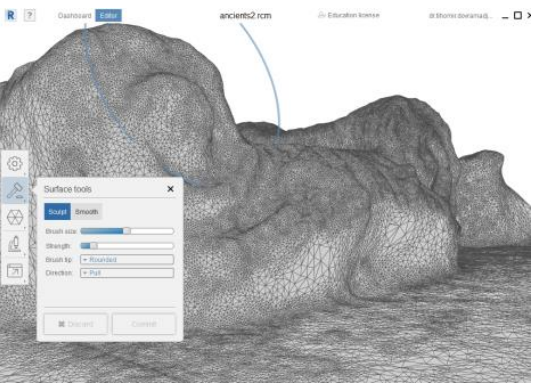

(c)

Figure 11. The stone stone voluta: real photo (a) $3 D+$ texture (b) and $3 D$ mesh (c) 


\section{Model 5. Ancient artifact - the stone scene}

The photogrammetry result from 21 captured photos (figure 12)

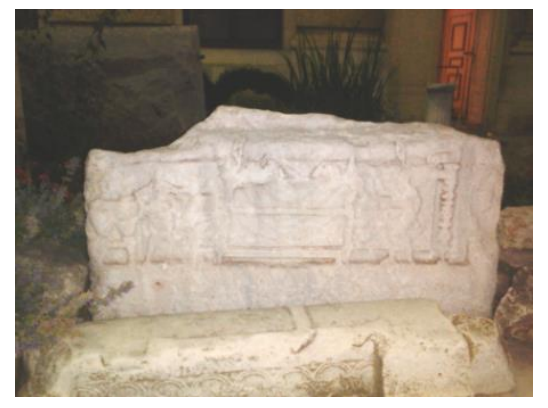

(a)

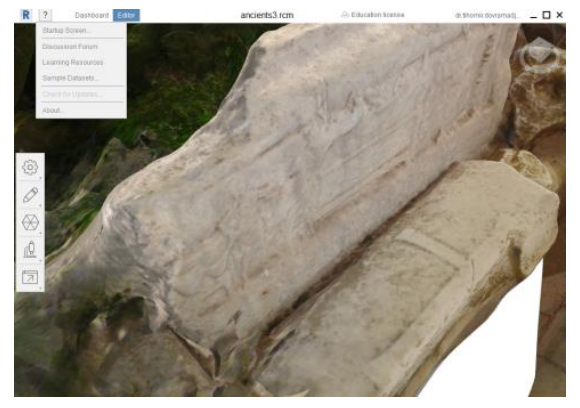

(b)

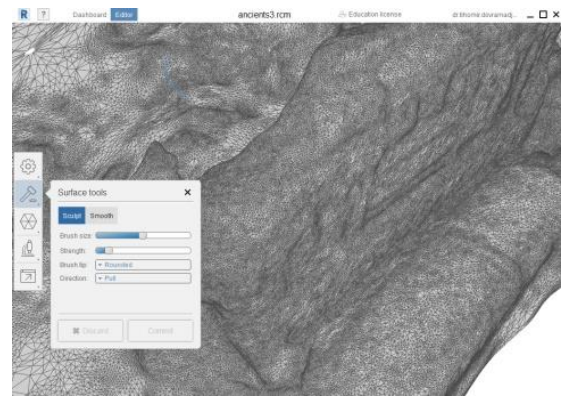

(c)

Figure 12 The stone scene: real photo (a) 3D + texture (b) and $3 D$ mesh (c)

\section{Conclusion}

The application of advanced technologies in photogrammetric design enables digital storage of models, objects, sculptures and others items with high historical value. Through the use of optimized process, data transfer and individual technical capabilities, 3D models with qualitative geometry are digitally completed.The obtained results are fully compatible and suitable for further development and application in the creation of virtual libraries and museums, internet sites and smart phone applications with scientific and cultural focus. The resulting 3D geometry is precisely designed and with quality regarding the thick polygonal mesh which enables real materialisation.

The obtained results and the information from the present study would be of benefit to academic, scientific and other professionalists working in the field of photogrammetry, archeology, culture, design, etc.

\section{Acknowledgments}

The described work was carried out as part of the research "Advanced technologies in design"

\section{References}

[1] Varna Museum of Archaeology. http://www.archaeo.museumvarna.com/en/

[2] Bulgaria online.bg. Municipality of Varna. http://bulgariaonline.bg/catalog/12652_obshtina_varna.html

[3] WorldAtlas. Political Map Of Europe. https://www.worldatlas.com/webimage/countrys/eupoliticallg.htm

[4] Sabori.bg Chalcolithic necropolis. http://www.sabori.bg/Oldest_gold.html

[5] Varna Museum of Archaeology. $\quad$ Prehistory. http://www.archaeo.museumvarna.com/en/category/list?category_id=3\&id=18

[6] LiveScience. What is the Golden Ratio?. https://www.livescience.com/37704-phi-goldenratio.html 
International Journal of Engineering and Management Sciences (IJEMS) Vol. 4. (2019). No. 1

DOI: 10.21791/IJEMS.2019.1.57.

[7] Melange Bulgaren. Tajnoto znanie na chernomorskata Atlantida. http://www.bulgaren.org/melangebulgaren/2014/10/30/тайното-знание-начерноморската-атла/

[8] Varna eye. Varna Museum Archaeology. http://www.varnaeye.com/bg/history/muzei/arheologicheski-muzei.html

[9] Varna Museum of

http://www.archaeo.museumvarna.com/en/category/list?category_id=6\&id=7

Archaeology.

[10] Ines Travel. Ancient golden treasures. http://www.inestravel.bg/tour_224.html

[11] Wikipedia. Photogrammetry. https://en.wikipedia.org/wiki/Photogrammetry\#cite_note-1

[12] Wikipedia data model of photogrammetry https://en.wikipedia.org/wiki/Photogrammetry\#/media/File:Photogrammetry_Wiora_EN.svg

[13] Wikipedia 3D data acquisition and object reconstruction. https://en.wikipedia.org/wiki/3D_data_acquisition_and_object_reconstruction

[14] C. Pereira - F. Henriques - N. Carriço - V. Amaral - T. Ferreira - A. Candeiass (2016) Virtual historical reconstitution of the main altarpiece of the Espírito Santo Church, in Évora: Application of web-based infographics to Cultural Heritage. Conservar Património24. pp. 63-71. doi:10.14568/cp2015034ARP - AssociaçãoProfissional de Conservadores-Restauradores de Portugal. ISSN 2182-9942,

[15] F. Henriques - J. Salgueiro - A. B. Gonçalves - A. Candeias - E. S. Vieira (2016) Arqueologia 3D: Um inventário de objetos do Museu de Arte Sacra e Arqueologia do Porto (Colecção D. Domingos de Pinho Brandão). Conference: 1ำ Colóquio de Investigações em Conservação de Património. DOI: 10.13140/RG.2.2.23832.70407

[16] P. Sapirstein (2018) A high-precision photogrammetric recording system for small artifacts. Journal of Cultural Heritage. 31 (33):45 DOI: 10.1016/j.culher.2017.10.011

[17] C. Allan - B. Wallace (2016) Photogrammetry in Mediterranean Archaeology. University of Waterloo.

[18] C. Allan - B. Wallace (2017) Retrospective Photogrammetry in Greek Archaeology. Studies in Digital Heritage. 1 (2) Publication date: December (2017). DOI: 10.14434/sdh.v1i2.23251

[19] T. Dovramadjiev (2017) High Quality Photogrammetry Modeling. ResearchGate. DOI: 10.13140/RG.2.2.13413.09447

[20] Autodesk ReCap software. https://www.autodesk.com/products/recap/overview

[21] Blender software. https://www.blender.org/

[22] Autodesk Mesh Mixer software. http://www.meshmixer.com/

[23] J. Kaufman - A. Rennie - M. Clement (2015) Single Camera Photogrammetry for Reverse Engineering and Fabrication of Ancient and Modern Artifacts. Published by Elsevier B.V. This is an open access article under the CC BY-NC-ND license (C) 2015). DOI: 10.1016/j.procir.2015.01.073

[24] T. Dovramadjiev (2017) 3D computer processing and improvement of the geometry ofreceived photogrammetric models through photo shooting with one camera. $5^{\text {th }}$ International Scientific Conference on Advances nn Mechanical Engineering. (Iscame2017) 12-13 October, 2017 Debrecen, Hungary. ISBN 978-963-473-304-1. pp. 115-122.

[25] T. Dovramadjiev (2018) Photogrammetry methodology, digitalization of sculpting models \& design. TUV and UWB. ResearchGate. DOI: 10.13140/RG.2.2.35691.64804 